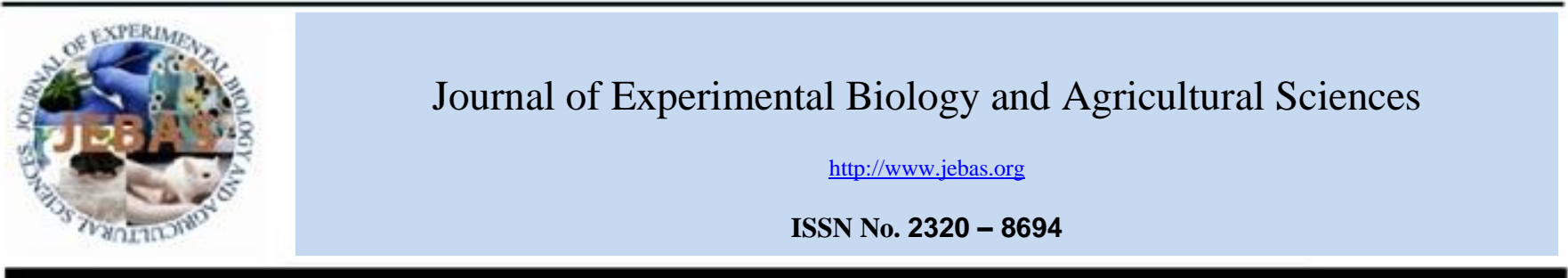

\title{
EVALUATION OF FORMOL GEL SLIDE TEST WITH REFERENCE TO BLOOD MICROSCOPY AND ENZYME LINKED IMMUNOSORBANT ASSAY FOR DIAGNOSIS OF SURRA IN CATTLE
}

\author{
P.C. Sarmah ${ }^{1}$, P. Kakati ${ }^{1}$, K. Bhattacharjee ${ }^{1}$, Prabhat Kumar ${ }^{2}$, S.C.Yadav ${ }^{2 *}$ \\ ${ }^{1}$ Department of Parasitology, College of Veterinary Science, Khanapara, Guwahati, Assam (India) \\ ${ }^{2}$ ICAR-National Research Centre on Equines, Sirsa Road Hisar-125001. Haryana (India)
}

Received - January 05, 2018; Revision - April 02, 2018; Accepted - April 24, 2018

Available Online - April 25, 2018

DOI: http://dx.doi.org/10.18006/2018.6(2).437.442

\section{KEYWORDS}

Trypanosoma evansi

Surra

Cattle

Formol Gel Slide test

ELISA

Wet Blood Examination

\begin{abstract}
The objective of the present study was to evaluate the conventional Formol Gel Slide Test (FGST) vis-avis Enzyme Linked Immunosorbant Assay (ELISA) in diagnosis of Trypanosoma evansi infection in cattle. In all, 51 adult Holstein-Friesian cattle were categorised in three groups i.e T. evansi positive symptomatic, parasite negative symptomatic and apparently healthy from 12 animal sheds at Guwahati, Assam. The FGST was performed with some modifications and results obtained were compared with blood smear findings and ELISA. The serum samples obtained from symptomatic cattle with or without detectable parasite in blood were found positive in the FGST as evidenced by immediate gellification and opacity development akin to white of a boiled egg. When compared to ELISA, the sera from clinical cases with high antibody titre (OD value >0.736) were found positive in FGST, while those from asymptomatic cattle with lower antibody titre, (OD value $<0.736$ ) were all negative in the test. Thus the detection performance of blood microscopy, FGST and ELISA were found to be $3.92 \%, 5.88 \%$ and $17.64 \%$ respectively. The study also suggests that ELISA as usual is more sensitive and suitable for screening of cattle herds during epidemiological investigation. However, the study revealed FGST to be a suitable, simple to perform and low cost screening test for field diagnosis of surra in clinically suspected cattle.
\end{abstract}

* Corresponding author

E-mail: yadavsc@ rediffmail.com (Dr S. C. Yadav)

Peer review under responsibility of Journal of Experimental Biology and Agricultural Sciences.

Production and Hosting by Horizon Publisher India [HPI] (http://www.horizonpublisherindia.in/).

All rights reserved.
All the article published by Journal of Experimental Biology and Agricultural Sciences is licensed under a Creative Commons Attribution-NonCommercial 4.0 International License Based on a work at www.jebas.org.

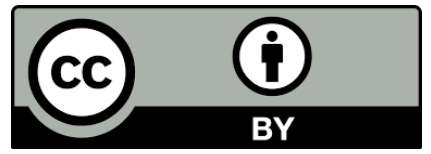




\section{Introduction}

Trypanosoma evansi is one of the most pathogenic trypanosome that infects different animal species in many parts of the world including India. The haematophagus dipteran flies especially the tabanid flies are the mechanical vectors of this trypanosome, which is transmitted from animal to animal in nature. The infection in cattle and buffaloes are usually cryptic in nature and leads to a carrier state that usually remains unnoticed (Jaiswal et al., 2015), yet capable of affecting their production potentialities (Muraleedharan, 2015). The carrier status may often become patent in the face of multiple stresses (Rani et al., 2015) resulting into per acute, acute or chronic clinical forms. Epizootics of the infection with profound morbidity and mortality have been reported in different species of animals including cattle and buffaloes (Singh et al., 2014).

Diagnosis of surra in cattle and buffaloes is difficult due to cryptic nature of infection, which interferes in gathering adequate information on the epidemiology of the disease. Infected cattle in clinical cases often exhibit nervine symptoms, corneal opacity and oedema of dependant parts in addition to lethargy, intermittent fever, progressive anaemia and emaciation. The routine laboratory methods available at present for diagnosis of infection are the microscopic examination of blood in wet film, stained smear and buffy coat preparations. However, finding of parasite in blood is very uncertain due to latent carrier status, low grade or intermittent parasitaemia in clinical cases. Several serological tests have been developed for detection of parasite antigen or antibodies in T. evansi infected animals (Jeyabal et al., 2003; Kumar et al., 2013; Yadav et al., 2014). These tests although specific with varying sensitivities are more suitable for herd screening in a geographical location. The polymerase chain reaction (PCR) based molecular techniques although claimed to be the most sensitive and specific, might generate false negative result owing to the fluctuating parasitaemia (Tehseen et al., 2017). Thus, these advanced methods despite their sensitivity and specificity cannot be employed in all field situations (Bal et al., 2014) due to lack of trained personnel, well equipped laboratory and rapid diagnostic facilities. Several chemical tests based on detection of rise in serum immunoglobulin level were employed in the past to diagnose surra in animals (Gill, 1991; Iqbal et al., 2012). One of those, the Formol Gel Test (FGT) also known as Napier's aldehyde test described by Napier (1922) for field diagnosis of suspected cases of visceral leishmaniasis (VL) in human patient was applied for the first time in diagnosis of surra in camels in Algeria and Sudan (Bhatia \& Shah, 2001). This test although abandoned due to its non-specificity is still known to provide dependable result that facilitates tentative diagnosis of camel surra and VL of man in developing countries where improved and rapid diagnostic facilities are scarce (Chappuis et al., 2005; Nazmulahasan et al., 2008). The performance of FGT in comparison with other improved serological and molecular methods has been evaluated for diagnosis of surra in camels and horses (Aslam et al., 2010; Tehseen et al., 2015). The present study was undertaken to evaluate the FGST with reference to blood microscopy and enzyme linked immunosorbant assay (ELISA) towards detection of T. evansi infection in cattle

\section{Materials and Methods}

The study was conducted in 12 cattle sheds owned by marginal farmers at Guwahati, Assam (India). In all, 51 adult cross bred (Holstein-Friesian) cows were made available for the investigation. The animals were reported to be apparently healthy, except for three animals from a shed, which had history of intermittent fever, dullness, anorexia, gradual drop in milk yield, oedema in hind legs and non responsive to symptomatic treatment. Blood of two of the clinical cases was also microscopically positive for T. evansi.

\subsection{Sample collection}

Individual blood samples were obtained from the jugular vein and placed partly in a heparinized tube and serum separator tube with clot activator. Heparinized blood samples were microscopically examined in wet film and Giemsa stained thin film preparations. Clotted blood tubes were centrifuged at $2000 \mathrm{rpm}$ and sera separated out for storage at $-20^{\circ} \mathrm{C}$ until use.

\subsection{Blood microscopy}

Wet blood film and giemsa stained smears were examined under high power (40X) and oil immersion (100X) for detection of $T$. evansi.

\subsection{Formol Gel Slide Test (FGST)}

This test was performed as per the method described by Chappuis et al. (2005) and Tehseen et al. (2015) with modifications. Briefly, $100 \mu 1$ test serum was placed in a cavity microslide and $10 \mu 1$ of concentrated formalin (37\% formaldehyde) was added and thereafter mixed by gentle tilting of the slide. Observation was made for 20 min to visualize gellification of the test serum and simultaneous development of opacity, if any. A positive test was indicated by the formation of gel that adhered to the slide and development of opacity like the white of a boiled egg. Formation of precipitation at the bottom of the slide with a clear surface fluid running off the slide, when tilted as seen in the test using foetal bovine serum (negative control) was considered negative (Figure 1). 


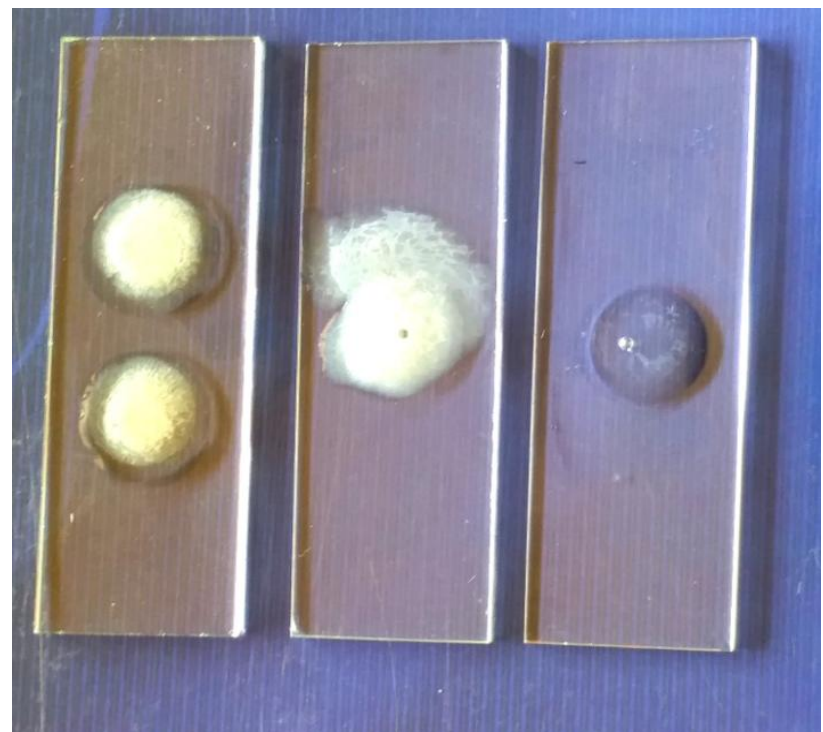

Figure 1 Formol Gel Slide Test results:

a(left)- Negative test serum showing precipitation with clear surface; $\mathrm{b}$ (middle)- Positive test serum showing gelification and opacity like white of a boiled egg;

$\mathrm{c}$ (right)- Negative control using foetal bovine serum.

\subsection{Enzyme Linked Immunosorbant Assay (ELISA)}

Briefly, a series of checkerboard titrations were conducted to determine the optimum concentration of $T$. evansi whole cell lysate antigen (WCL cattle origin) and conjugates for use in ELISA assay. ELISA plates (Nunc) were coated with $50 \mu 1$ of 1.0 $\mathrm{mg} / \mathrm{ml}$ of antigen in $0.1 \mathrm{M}$ carbonate/bicarbonate buffer ( $\mathrm{pH} 9.6$ ) per well. Blocking was done with $100 \mu \mathrm{l}$ of $5 \%$ skimmed milk in PBST (SM-PBST) for $1 \mathrm{~h}$ at $37^{\circ} \mathrm{C}$. Subsequently, after washing $50 \mu 1$ of test serum (1:100 diluted in $5 \%$ SM-PBST) were added to each well and incubated for $1 \mathrm{~h}$ at $37{ }^{\circ} \mathrm{C}$. Thereafter, $50 \mu \mathrm{l}$ of 1:4000 diluted anti bovine $\mathrm{IgG}$-peroxidase conjugate (Sigma) was added to each well after washing and the plates incubated for $1 \mathrm{~h}$ at $37{ }^{\circ} \mathrm{C}$. Thereafter, substrate Tetra methyl benzidine (Genei, India) $50 \mu 1$ was added and reaction was stopped by adding $50 \mu 1$
$0.5 \mathrm{~N} \mathrm{H}_{2} \mathrm{SO}_{4}$ to each well. The absorbance was read at $450 \mathrm{~nm}$ on ELISA reader (Thermo scientific, MULTISKAN GO, Finland) and results were expressed as mean OD of duplicate samples. The cut off values were determined using mean OD \pm 3 SD of uninfected serum samples from the herd.

\section{Results and Discussion}

The results of blood microscopy, FGST and ELISA are presented in Table 1. Out of the 12 cattle sheds examined, animals from 6 (50\%) sheds were found positive for antibodies to T. evansi in ELISA. Animals of only one shed tested positive to T. evansi in giemsa stained blood smear examination and serum analysis by FGST (Table 1). Three animals from this affected shed were reported clinically ill and their serum samples were found positive in both the serological tests conducted. However, out of three, one animal showed presence of $T$. evansi parasites in giemsa stained smear examination. Further, test wise, the infection was recorded in $3.92 \%, 5.88 \%$ and $17.64 \%$ of animals tested by microscopic examination, FGST and ELISA respectively (Figure 2). No study comparing the performance of FGST and ELISA has been reported in cattle sera. However, the results are in agreement with that of Aslam et al. (2010) who observed a good correlation among FGT, Ab-ELISA and PCR performed in horse suspected for T. evansi infection by FGT. Tehseen et al. (2015) also observed uniform result in FGST and ELISA conducted in camels.

The results of microscopic examination, ELISA and FGST were found to be uniform in two of the symptomatic cattle. However, despite FGST and ELISA positive result, the blood of the third symptomatic cattle was found parasite free, which might be due to inconsistent and fluctuating parasitaemia (Yadav et al., 2016). The ELISA data showed that $3 / 9(33.3 \%)$ cattle sera with high antibody titre (O.D value $>0.736$ ) from symptomatic cattle were FGST positive (Table 2). Moreover, low antibody titre of sera from apparently healthy cattle as observed in the present study may be attributed to T. evansi carrier stage of infection.

Table 1 Performance of blood microscopy, FGST and ELISA conducted in cattle in detection of infection.

\begin{tabular}{|cccccc|}
\hline Area & $\begin{array}{c}\text { No. of Animal sheds } \\
\text { attended }\end{array}$ & $\begin{array}{c}\text { No. of animal } \\
\text { sampled }\end{array}$ & Blood microscopy & FGST & Percent animal positivity to T. evansi \\
\hline $\begin{array}{c}\text { I } \\
\text { Ganeshguri }\end{array}$ & 7 & 26 & - & - & $11.53(3)$ \\
\hline $\begin{array}{c}\text { II } \\
\text { Jatiya }\end{array}$ & 3 & 15 & $40.0(2)$ & $60.0(3)$ & $8.6(1)$ \\
\hline $\begin{array}{c}\text { III } \\
\text { Ambari }\end{array}$ & 1 & 5 & - & - & $20.0(4)$ \\
\hline $\begin{array}{c}\text { IV } \\
\text { Cycle Factory }\end{array}$ & 1 & 5 & $3.92(2)$ & $5.88(3)$ & $17.64(9)$ \\
\hline Total & 12 & 51 & $(9)$ \\
\hline
\end{tabular}

Figures in parenthesis indicate number of positive cattle.

Journal of Experimental Biology and Agriculture Science http://www.jebas.org 


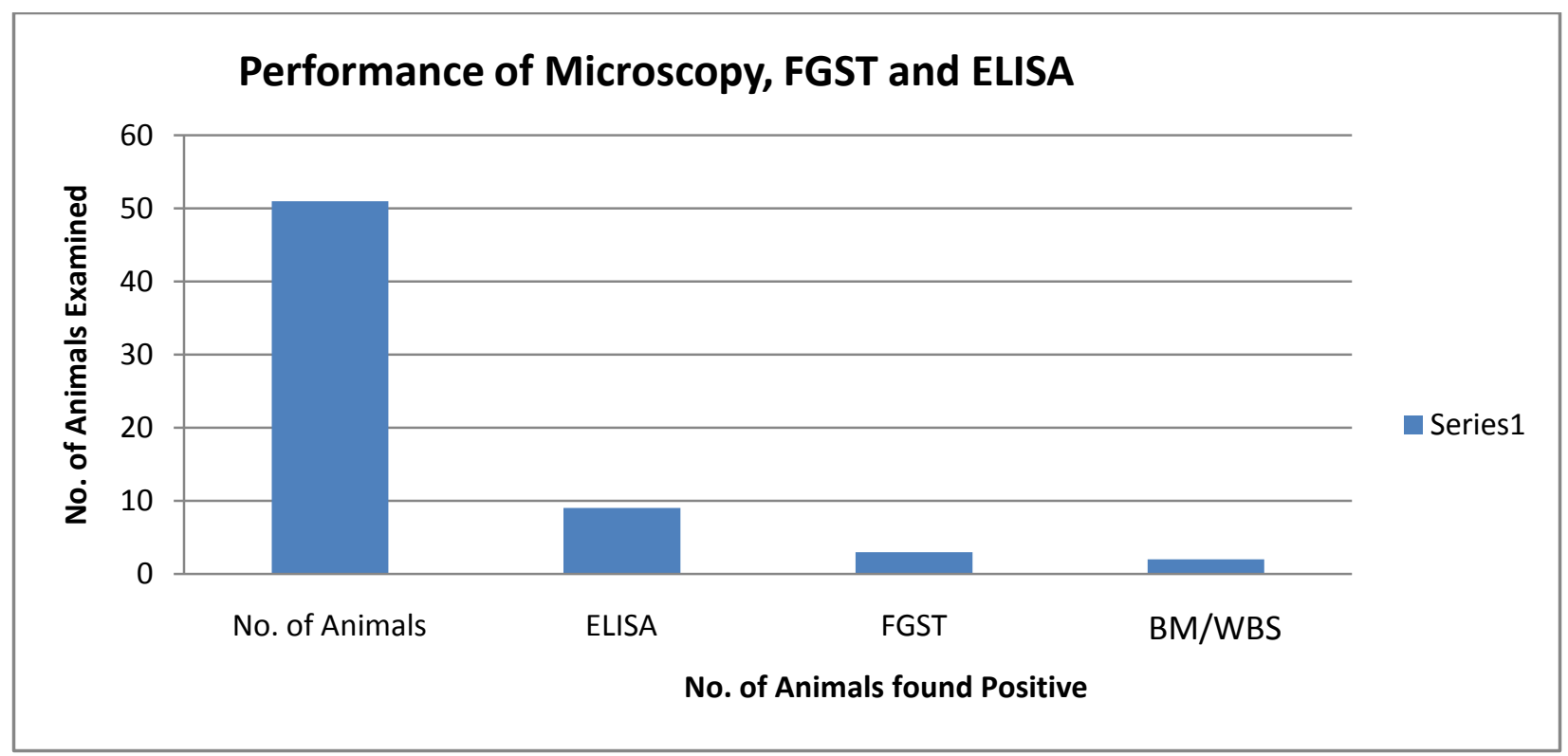

Figure 2 Bar diagram showing performance of Blood Microscopy, FGST and ELISA in diagnosing T. evansi infection in cattle.

Table 2 Performance of Formol Gel Slide test in relation to positive ELISA in cattle serum samples

\begin{tabular}{|cccc|}
\hline $\begin{array}{c}\text { Animal } \\
\text { Sl. No. }\end{array}$ & $\begin{array}{c}\text { Serum sample } \\
\text { No. }\end{array}$ & $\begin{array}{c}\text { OD value }^{1} \text { in } \\
\text { ELISA }\end{array}$ & $\begin{array}{c}\text { Result of } \\
\text { FGST }\end{array}$ \\
\hline 2 & 11 & 0.2563 & -ve \\
\hline 3 & 21 & 0.2202 & -ve \\
\hline 4 & 25 & 0.7356 & -ve \\
\cline { 2 - 4 } & $27(\mathrm{a})^{*}$ & 0.84425 & $+\mathrm{ve}$ \\
\hline 5 & $27(\mathrm{~b})^{* *}$ & 0.30635 & $-\mathrm{ve}$ \\
\hline 6 & $28(\mathrm{a})^{*}$ & 1.0799 & $+\mathrm{ve}$ \\
\hline 7 & $28(\mathrm{~b})^{* *}$ & 0.5312 & $-\mathrm{ve}$ \\
\hline 8 & 29 & 1.07245 & $+\mathrm{ve}$ \\
\hline 9 & 43 & 0.2277 & $-\mathrm{ve}$ \\
\hline & 52 & 0.2588 & $-\mathrm{ve}$ \\
\hline
\end{tabular}

Blood Sampling: * Pre treatment, Aug., 2014; ** Post treatment (Seven month) March, 2015, ${ }^{1}$ Cut off value 0.22075 at $450 \mathrm{~nm}$

Positive FGST result obtained in line with other tests performed in the present study indicates that the test is still useful and may be supporting evidence for diagnosis of clinical surra. The present findings are consistent with those observed in the similar tests conducted in parasitologically proven or suspected cases of VL in human (Chappuis et al., 2005; Parveen et al., 2007). There have been contradicting reports on validity of FGST for diagnosis of surra in cattle (Ray \& Bhaskaran, 1953; Gill, 1991). However, satisfactory result obtained in clinical cases of the present study agrees to the earlier reports in camels and horses (OIE, 2010; Aslam et al., 2010; Tehseen et al., 2015) and also in cattle (Goel \& Singh, 1971; Krishnappa et al., 2002) and dog (Poul, 1950; Farrar et al., 2013). Uniform result that can be obtained in hosts irrespective of their species re-affirms that the test is a useful one as an indicator of hyperglobulinaemia, an important biochemical alteration observed in trypanosomiasis and visceral leishmaniasis (Singla et al., 2000; Kaur \& Juyal, 2003; Chappuis et al., 2005; Bal et al., 2014). Thus the present study suggests that FGST is a simple test and can be performed even under field condition at a very negligible cost for a quick decision in individual clinical cases of suspected surra in cattle also.

Compared to the north western and northern India (Singh \& Chabbra, 2008), documentation of clinical surra from the north eastern region of India is very scanty. This might be due to very small equine population and absence of camel which are the primary hosts of $T$. evansi. However, this region has been experiencing regular inward transportation of high yielding cattle for milk production from the surra endemic north India. Increasing unregulated cattle transportation for private trade might be a prime factor (Fevre et al., 2006; Selby et al., 2013) responsible for spread of surra to this region. The recent report of clinical surra (Sarmah et al., 2015) and further evidence of positive results as observed in the clinical and apparently healthy 
cattle in the present study may raise an alarm to the field veterinarians on the threat of dormant $T$. evansi infection in cattle and its possible excerbation under different stress related conditions.

FGST a rapid and simple low cost traditional tool may still find place in tentative diagnosis of clinical surra in cattle, similar to that of camels and horses of developing or under developed countries where more efficient rapid tests are yet to take off for field diagnosis.

\section{Acknowledgement}

The authors are thankful to the Dean, Faculty of Veterinary Science, Khanapara, Guwahati-22 and Director, ICAR-National Research Centre on Equines, Hisar for providing facilities. The authors also wish to acknowledge and thank Sh. R. K Dayal, Senior Technical Assistant for technical support during the investigation.

\section{Conflict of Interest}

Authors would hereby like to declare that there is no conflict of interests that could possibly arise.

\section{References}

Aslam A, Chaudhary ZI, Rehman H, Ashraf A, Ahmad N, Maqbool A, Shakoori AR (2010) Comparative evaluation of parasitological, serological and DNA amplification methods for diagnosis of natural trypanosomal infection in equines. Pakistan Journal of Zoology 42: 371- 376.

Bal MS, Sharma A, Ashuma, Bath BK, Kaur P, Singla LD (2014) Detection and management of latent infection of Trypanosoma evansi in a cattle herd. Indian Journal of Animal Research 48: 3137.

Bhatia BB, Shah HL (2001) Protozoa and Protozoan diseases of domestic livestock. ICAR, New Delhi, Pp.202.

Chappuis F, Muller Y, Nguimfack A, Rwakimari JB, Couffignal S, Boelaert M, Cavailler P, Loutan L, Piola P (2005) Diagnostic accuracy of two rk39 antigen based dipsticks and formol gel test for rapid diagnosis of visceral leishmaniasis in north eastern Uganda. Journal of Clinical Microbiology 43: 5973-5977.

Farrar J, Hoetz P, Junghanss T, Kang G, Laloo D, White N (2013)

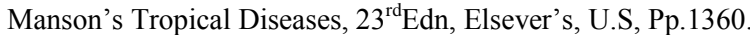

Fevre EM, Bronsvoort BM, Hamilton KA, Cleaveland S (2006).Animal movements and the spread of infectious diseases. Trends in Microbiology 14: 125-31.
Gill BS (1991) Trypanosomes and trypanosomiasis of Indian Livestock. $2^{\text {nd }}$ Ed. Indian Council of Agricultural Research, New Delhi, India. 192 pp.

Goel SK, Singh RP (1971) Comparative studies on certain diagnostic tests in the diagnosis of Surra. Journal of Research 8: 404-406

Iqbal M, Singh R, Wani N, Irfan M (2012). Trypanosomiasis - An impediment to livestock development. International Journal of Livestock Research 2: 52-57.

Jaiswal AK, Vikrant S, Neha, Verma AK (2015). Insight into trypanosomiasis in animals: various approaches for its diagnosis, treatment and control-A review. Asian Journal of Animal Sciences 9: 172- 186.

Jeyabal L, Chaudhuri SS, Singh A, Kumar D (2003) Detection of circulating antigens in immune complexes of Trypanosoma evansi infected cattle and buffaloes by ELISA. Journal of Veterinary Parasitology 17: 85-88.

Kaur P, Juyal PD (2003) Haematobiochemical changes in experimental surra in cow calves treated with diminazene aceturate along with antipyrine and procaine. Indian Veterinary Journal 80: 975-978.

Krishnappa T, Muralidhara A, Sastry KNV, Renukaprasad C, Krishnappa G (2002) Prevalence of trypanosomiasis in domestic animals in Karnataka. Indian Veterinary Journal 79: 183-184

Kumar R, Kumar S, Khurana SK, Yadav SC (2013) Development of an antibody- ELISA for seoprevalence of Trypanosoma evansi in equids of north and north western regions of India. Veterinary Parasitology 196: 251-257.

Muraleedharan K (2015) An update on Trypanosoma infection in livestock of Karnataka state, India. Veterinary Research International $3: 46-54$.

Napier LEA (1922) New serum test for Kala- azar. Indian Journal of Medicinal Research $9: 830$.

Nazmulahasan H, Ayaz KFM, ShafiqulBari MD (2008) Current diagnosis and treatment of kala azar: Bangladesh Perspective. Journal of Medicine $9:$ 45-49.

OIE (2010) Trypanosoma evansi infection (Surra). OIE Terrestrial Manual, Chapter 2.1.17, 1-13 p.

Parveen R, Rahman ME, Islam MN, Uddin SN, Khlaeque MA, Choudhury AM (2007) Diagnostic efficacy of aldehyde test in late cases of Kala-azar. Mymensingh Medical Journal 16: 160-164. 
Poul J (1950) Incidence of leishmaniasis in dogs in Algeria and the value of formol gel test in diagnosis. Archives De l'Institut Pasteur De Madagascar 28 : 449-456.

Rani NL, Suresh K, Rajesh K (2015) A retrospective study on clinico-epidemiological aspects of trypanosomiasis in buffaloes. International Journal of Veterinary Science 4 : 97-100.

Ray HN, Bhaskaran R (1953) Chemical tests in bovine surra. Indian Veterinary Journal $30:$ 236- 240.

Sarmah PC, Dewan JN, Bhattacharjee K, Choudhury R, Sarma M, Borgohain R (2015) Oriental theileriosis and Surra in a holsteinFriesian cattle shed: Herd investigation, haematology and therapeutic management. International Journal of Recent Scientific Research 6 :6536- 6538.

Selby R, Bardosh K, Picozzi K, Waiswa C, Welburn C (2013) Cattle movements and trypanosomes: restocking efforts and the spread of Trypanosoma brucei rhodesiense sleeping sickness in post conflict Uganda. Parasites \& Vectors 6: 281

Singh V, Chabbra MB (2008) Trypanosomiasis (Surra) in India:An update. Journal of Parasitic Diseases 32: 104-110.

Singh D, Kumar S, Singh B, Bardhan D (2014) Economic losses due to important diseases of bovines. Veterinary World 7: 579-585.
Singla LD, Juyal PD, Ahuja SP (2000) Serum protein changes of cross bred calves experimentally infected with Trypanosoma evansi and immunomodulated with levamisole. Indian Veterinary Journal 77: 172-174.

Tehseen S, Jahan N, Desquesnes M, Shahzad MI, Qamar MF (2017) Field investigation of Trypanosoma evansi and comparative analysis of diagnostic tests in horses from Bahawalpur,Pakistan. Turkish Journal of Veterinary \& Animal Sciences $41: 288-293$.

Tehseen S, Jahan N, Qamar MF, Desqueshes M, Shahzad MI, Deborggraeve S, Buscher P (2015) Parasitological, serological and molecular survey of Trypanosoma evansi infection in dromedary camels from Cholistan desert, Pakistan. Parasite \& Vectors 8: 415- 425.

Yadav SC, Kumar R, Manuja A, Goyal L, Gupta AK (2014) Early detection of Trypanosoma evansi infection and monitoring of antibody levels by ELISA following treatment. Journal of Parasitic Diseases 38: 124-127.

Yadav SC, Kumar J, Gupta AK, Jerome A, Kumar P, Kumar R, Tehri K, Kumar R (2016) Parasitological, Biochemical and clinical observations in ponies experimentally infected with Trypanosoma evansi. Journal of Experimental Biology and Agricultural Sciences 4: (Spl-4-EHIDZ): S144-S150.

Journal of Experimental Biology and Agriculture Science http://www.jebas.org 